\title{
Estufa com aquecimento suplementar: um estudo avaliativo para agricultura familiar a partir da compostagem sustentável de pelos e estercos
}

\author{
Supplementary heating greenhouse: an evaluative study for family \\ agriculture from the sustainable composition of hair and manure
}

\author{
Aldeni Melo de Oliveira (aldeni-melo@hotmail.com) \\ Universidade do Vale do Taquari - Univates \\ Giovanne Tavares Ferreira (giovanne19996@gmail.com) \\ Universidade Estadual do Amapá - UEAP \\ Andreia Aparecida Guimarães Strohschoen (aaguim@univates.br) \\ Universidade do Vale do Taquari - Univates
}

Resumo: Este artigo analisou a problemática do destino dado aos pelos e estercos de gatos e cães domésticos e a produção de energia elétrica alternativa. Compreende-se que esta investigação apresenta responsabilidade sustentável nessa ação, por propor ideias alternativas e inovadoras para utilização de pelos e estercos liberados por animais que se encontram em muitas residências, como adubo fertilizante e substrato especial para o processo de agricultura sustentável. Objetivou-se neste estudo, construir uma composteira com técnicas sustentáveis, que permita transformar pelos e estercos de gatos e cães em matéria orgânica com fins agrícola, e gerar energia fotovoltaica. Metodologicamente, apresentou uma abordagem quali-quantitativa, com caráter descritivo e exploratório. A investigação ocorreu com alunos do $8^{\circ}$ e $9^{\circ}$ ano do Ensino Fundamental II em uma escola estadual do município de Macapá/AP. Foi analisada a construção de estufa com aquecimento suplementar e observação do crescimento de alface. A estufa permitiu o aquecimento e a utilização dos resíduos orgânicos em seu local de produção. Foi obtida nova forma de aproveitamentos de pelos e estercos de gato e cães, com energia fotovoltaica como fruto de técnicas sustentáveis, resolvendo uma questão socioambiental, com a apropriação de diferentes olhares para tais resíduos, com sensibilidade ambiental.

Palavras-chave: Agricultura; Compostagem; Energia limpa.

Abstract: This article analyzes a problem of fate given to hair and manure from domestic cats and dogs and the production of alternative eletricity. It is understood that this investigation presents sustainable responsibility in this action, for proposing alternative and innovative ideas for the use of hair and manure released by animals found in many homes, as fertilizer and special organic matter for the sustainable agriculture process. The objective of this study was, to build a composter with sustainable techniques that allows the transformation of cat and dog hair and manure into organic matter for agricultural purposes, and generate photovoltaic energy. Methodologically, presented a qualitative and quantitative approach, descriptive and exploratory. The investigation occurred with 8th and 9th grade students of Elementary School II, in a state school in the city of Macapá / AP. The construction of a greenhouse with supplementary heating and observation of lettuce growth was analyzed. The 
greenhouse allowed the heating and the use of organic waste at your production site. A new form of use hair and manure of cats and dogs was obtained, with photovoltaic energy as a result of sustainable techniques, solving a socio-environmental issue, with the appropriation of different perspectives for such residues, with environmental sensitivity.

Key words: Agriculture; Composting; Clean Energy.

\section{INTRODUÇÃO}

Nesta pesquisa, é apresentado, de maneira introdutória, o estudo que teve como objetivo, investigar a construção de uma estufa com técnicas sustentáveis permitindo transformar pelos e estercos de gatos e cães em matéria orgânica com fins agrícola, além de anexar painéis solares para produção de energia fotovoltaica.

A preocupação dos criadores de cães e gatos com os destinos dos pelos e estercos dos mesmos, permitiu o surgimento da referida pesquisa. Visto que, o intenso convívio entre os animais e o ser humano concebe a parcela mais significativa de espécies introduzidas no âmbito das relações humanas, animais de estimação, igualmente conhecidos como "pets".

O Instituto de Brasileiro de Geografia e Estatística (IBGE) apresentou em 2013, dados referentes à Pesquisa Nacional de Saúde (PNS) em relação aos animais de estimação nas residências dos brasileiros. O Instituto estimou a população de cães em domicílios brasileiros em 52,2 milhões, o que dá uma média de 1,8 cães por domicílio que tem pelo menos um cão em suas dependências.

Compreende-se que, esta pesquisa apresenta responsabilidade com competência sustentável nessa ação por propor ideias alternativas e inovadoras para utilização de pelos e estercos liberados por animais que se encontram em muitas residências, como adubo fertilizante e substrato especial para o processo de agricultura sustentável - por não apresentar adubo industrializado. Proporcionando ao trabalhador rural uma melhor produtividade agrícola, uma vez que, depende da agricultura para sobrevivência. Ademais, a pesquisa promove uma destinação adequada da matéria orgânica liberada naturalmente por gatos e cães.

Esta pesquisa apresenta uma investigação científica desde a compostagem da terra, substrato especial para o cultivo, análise dos pelos e estercos de gatos e cães, a 
avaliação de fertilidade e textura do solo até a temperatura elevada a partir da estufa e o aquecimento suplementar com as peças de espelhos. Os painéis solares na parte superior da composteira obtiveram grande relevância, pois fundamenta na conversão fotovoltaica que, de acordo com Villalva (2015), é uma fonte de energia limpa, que não tem emissões indesejáveis, e renováveis, devido à natureza inesgotável do sol.

\section{DESCRIÇÃO DE MATERIAIS E MÉTODOS}

O método de pesquisa é de simples observação e percorreu desde a problemática dos pelos e estercos liberados por animais específicos. Os experimentos realizados ao logo da pesquisa e resultados obtidos foram registrados em um diário de bordo, assim como reflexões que impulsionaram o passo inovador para o desenvolvimento de forma inovadora a investigação apresentada.

A pesquisa foi desenvolvida na escola estadual Irmã Santina Rioli de Ensino Fundamental II, no município de Macapá-AP. Os sujeitos que realizaram as intervenções são alunos do $8^{\circ}$ e $9^{\circ}$ ano na escola, os quais têm o Termo de Consentimento Livre e Esclarecido - TCLE dos pais, no período de 03 de maio de 2019 a 30 de junho de 2020, com questionamentos direcionados a criadores de gatos e cães, e seus nomes dos foram preservados por motivo de ética e sigilo.

Esta investigação designou-se uma pesquisa quali-quantitativa a partir de um caminho metodológico que, direcionou análise coesa da problemática no que diz respeito a liberação de pelos e estercos de gato e cães, compostagem, coleta de dados, testes químicos, granulométricos, grupo controle com alfaces, análises de temperatura, conversão fotovoltaica e contribuições agrícolas.

A abordagem de pesquisa quali-quantitativa "interpreta as informações quantitativas por meio de símbolos numéricos e os dados qualitativos mediante a observação, a interação participativa e a interpretação do discurso dos sujeitos (semântica)" (KNECHTEL, 2014, p. 106).

O mesmo posicionamento é apresentado e acrescentado por Grácio e Garrutti (2005), ao argumentarem que, é indispensável convergir a área de Educação com a quantificação, pois isto permite um entendimento de maneira mais ampla e completa da problemática que é encontrada no decorrer da realidade pesquisada. De acordo com os 
autores, "as quantificações fortalecem os argumentos e constituem indicadores importantes para análises qualitativas” (GRÁCIO; GARRUTTI, 2005, p. 119).

A presente investigação apresenta caráter exploratório ao analisar dados que correspondem ao objetivo de estudo, por permitir uma delimitação no campo de pesquisa da referida investigação. A investigação ainda incluiu uma pesquisa-ação no ponto de vista técnico-metodológico, pois foram realizadas intervenções para responder os objetivos propostos. Baseou-se no direcionamento de Thiollent (2011), pois o autor afirma que, a pesquisa-ação consente realizar uma estreita associação com apoio em uma ação ou analisar um problema de forma coletiva entre os participantes, com intuito de fazer os envolvidos participarem ou contribuírem na modificação da realidade e na construção de conhecimento a partir dessas variações.

Para os instrumentos de coleta de dados, foram propostos nos aportes teóricos de Lakatos e Marconi (2011), os quais apresentam a proposta de verificação à observação e à experimentação, com atividades experimentais que são controláveis e, bem como permitido a reprodução. Assim, o método de coleta de dados se efetuou por meio de aplicação de questionários, com proposições abertas e fechadas, as quais objetivaram conhecer a problemática social de criadores de gatos e cães sobre a quantidade e destino dado aos pelos e estercos de seus respectivos gatos e cães; construção da composteira através do efeito estufa, com e sem aquecimento suplementar; carregamento total de duas baterias através de painéis solares; testes químicos e granulométricos de amostras de solos e grupo controle com vegetais da Família: Lactuca sativa do Gênero: Lactuca, popularmente conhecido como alface, cultivados em diferentes tipos de compostos.

Para os testes com estercos de gatos e cães, os resíduos foram coletados e realizados compostos no próprio domicilio onde residem os animais domésticos, que são desverminados trimestralmente, alimentados por ração com as características nutricionais, registradas no diário de bordo.

Os registros dos valores nutricionais das rações foram realizados por compreender a afirmação de França et al. (2011), que afirma que, as rações comerciais para animais de estimação são legisladas para consentir todas as precisões específicas de nutrientes em diferentes estados fisiológicos de cães e gatos. $\mathrm{O}$ valor nutricional da ração para a manutenção da vida do animal deve estar de acordo com a Association of American 
Feed Control Officilas (AAFCO), pois é o órgão que determina as quantidades mínimas e máximas de nutrientes para os distintos estados fisiológicos dos cães e gatos.

As atividades experimentais e análises investigativas aconteceram em um terreno residencial - onde residiam gatos e cães, e no laboratório cientifico da escola estadual Irmã Santina Rioli. Os modelos de composteiras foram confeccionados reutilizando materiais alternativos e de baixo custo, disponíveis em lojas especializadas, com as seguintes características. Tabela 1.

Tabela 1 - Materiais para construir as três composteiras

\begin{tabular}{ccc}
\hline Unidades & Material & Dimensões \\
\hline $\mathbf{8}$ & Vidro 6,0mm & $50 \mathrm{~cm} \times 50 \mathrm{~cm}$ \\
\hline $\mathbf{4 5 0}$ & Pedaços de espelhos & $2 \mathrm{~cm} \times 2 \mathrm{~cm}$ \\
\hline $\mathbf{3}$ & Termômetros & $27 \mathrm{~cm}$ \\
\hline $\mathbf{3}$ & Baldes - coletores & 15 litros \\
\hline $\mathbf{2}$ & Placa solar & $31 \mathrm{~cm} \times 19 \mathrm{~cm}$ \\
\hline $\mathbf{2}$ & Baterias de lítio & $6 \mathrm{~W}-$ Watts \\
\hline
\end{tabular}

Fonte: Os autores, 2019.

Com a finalidade de avaliar a fertilidade e textura das amostras, foi realizada a compostagem durante três meses, com testes sem estufa; com estufa e estufa com aquecimento suplementar. Construíram-se, posteriormente, hortas sustentáveis em três grupos com quatro recipientes para cada grupo, cada recipiente recebeu dois cultivos de alfaces que permitiram fazer uma análise comparativa dos seus crescimentos, além de provar sua fácil aplicabilidade em qualquer ambiente. Ressalta-se que, os 12 recipientes receberam a mesma quantidade de terra e água durante os experimentos.

Para análise química e granulométrica, foram utilizadas amostras de terra. Posteriormente, analisou-se a energia gerada a partir dos sistemas fotovoltaicos a partir das tecnologias células fotovoltaicas, que geram correntes elétricas a partir dos raios solares. Para tanto, foram utilizadas duas baterias de lítio; dois painéis solares com cabo de 5 metros, com potencialidade de $6 \mathrm{~W}$ - Watts, com adaptação para fonte de alimentação para ligar até oito lâmpadas de led ou carregar celulares móveis com $5 \mathrm{~V}$ volte, os miliampere-hora.

\section{RESULTADOS E DISCUSSÃO}


Analisou-se a construção da composteira de forma alternativa a partir da problemática encontrada nas respostas dadas no questionário; as variações de temperatura em ${ }^{\circ} \mathrm{C}$ nas composteiras; produção de energia elétrica a partir dos raios solares posteriormente à conversão fotovoltaica; as propriedades químicas e granulométricas das amostras de terra com e sem estercos/pelos para uma avaliação da fertilidade e textura do solo.

Finalizou-se os resultados e discussões descrevendo estudo de grupo controle de vegetais da família Lactuca sativa do Gênero: Lactuca, cultivada em diferentes tipos de adubos através da construção de uma horta alternativa que permitiu as análises da pesagem da biomassa.

O questionário com perguntas abertas e fechadas, foi respondido por uma amostragem de 107 sujeitos, apresentado juntamente com o Termo de Consentimento Livre e Esclarecido - TCLE nos municípios de Santana e Macapá/AP, o que proporcionou os seguintes resultados: A idade dos questionados variou de 10 a 69 anos e deste total, $57 \%$ do sexo feminino e $43 \%$ do sexo masculino. Desse total, $55 \%$ criam cães, $30 \%$ criam cães e gatos e $15 \%$ criam somente gatos.

As profissões dos sujeitos que responderam o questionário são bem diversificadas, bem como: motorista, servente, educador penitenciário, auxiliar administrativo, maquiadora, tec. enfermagem, estudante, merendeira, enfermeira, contador, artesão, analista de sistema, doméstica, auxiliar de contabilidade, tec. massoterapia, policial militar, comerciante, professor, analista de TI, nutricionista, empresário, instrutor de dança, pedagogo e téc. radiologia.

A $1^{\text {a }}$ questão indagou se o criador de gatos e/ou cães tinha problemas com pelos e/ou estercos do seu animal de criação e obteve como resposta que 36\% não têm tal problema, enquanto 64\% afirmaram ter algum tipo de problema. Na mesma questão, foram solicitadas sugestões para os que têm problemas com pelos e/ou estercos e as sugestões foram: reaproveitar, pentear diariamente, criar em espaço específico, manter a pelagem sempre baixa, coletar esses materiais, coleta seletiva, enterrar, manter ambiente limpo, evitar contato, cooperativa e adestrar.

$\mathrm{Na} 2^{\mathrm{a}}$ questão, foi proposta uma reflexão sobre o quantitativo de estercos produzido pelos respectivos gatos e/ou cães semanalmente, as respostas foram as 
seguintes: $21 \%$ produzem até $3 \mathrm{~kg}, 20 \%$ produzem até $700 \mathrm{~g}, 19 \%$ até $250 \mathrm{~g}, 14 \%$ acima $8 \mathrm{~kg}, 14 \%$ até $5 \mathrm{~kg}$ de estercos e $12 \%$ afirma ser até $8 \mathrm{~kg}$.

Quando questionados se conheciam algum projeto que aproveitasse os pelos e/ou estercos de gatos e cães, $90 \%$ dos criadores de gatos e/ou cães afirma não conhecer e $10 \%$ afirma ter conhecimento de algum tipo de atividade de aproveitamento de tais materiais.

Para analisar a problemática da proposta desta pesquisa sobre o destino dado aos pelos e/ou estercos dos animais, de acordo com os questionados, os destinos são: lixo doméstico em quase sua totalidade, fossa, terreno da residência, esgoto, área de ressaca, terreno abandonado, ficam na tosa e queimado. Tornando assim, uma reflexão sobre a viabilidade da proposta apresentada.

Foi perguntado em qual local da residência mais acumula pelos dos gatos e/ou cães, e as respostas foram: quarto, cama, sofá, quintal, roupa, sala, pátio, tapetes, varanda, cozinha, área externa, área de serviço e garagem.

Para concluir a aplicação do questionário, foi solicitado aos criadores de gatos e/ou cães uma palavra que eles agregam à imagem positiva sobre seus gatos e/ou cães, e as palavras mais lembradas foram: amigo, companheiro, lealdade, carinho, felicidade, cuidado, amor, vida, brincar, alegria, fiel, protetor, dócil, diversão e tranquilidade. Ao solicitar aos questionados, palavras que os levam à uma imagem negativa sobre a criação de gatos e/ou cães, as mais listadas foram: odor, carrapato, doença, sujeira, bagunça, latido, arranhões, estresse, trabalho, escavador, abandono, fezes, solidão, bravo, fuga, morder, pelos, carência, urina, arranhar, fuga, tristeza e impaciência.

Assim, a contribuição do questionário foi importante, pois para Gil (2012) a aplicação de questionário é um excelente instrumento investigativo que pode ser combinado por distintas perguntas sobre determinados assuntos, onde o pesquisador deve de, com antecipação, delinear e buscar conseguir dados dos indivíduos a ele submetidos. Dessa forma, as perguntas que irão compor o questionário precisam ser claras e objetivas, podendo ser questões abertas, fechadas e/ou de múltiplas alternativas que permitam melhor entender a pesquisa.

Penteado (2013), contribui nesta discussão por afirmar que, a compostagem tem como benefícios contribuir com o melhor aproveitamento e destino dado aos resíduos 
orgânicos e consentir a utilização destes que, por sua natureza, seja ela física (grosseira), química ou biológica, não seriam aproveitados. O autor ressalta que, a transformação dos resíduos orgânicos em composto precisa ocorrer em condições controladas.

Ressalta-se ainda, segundo o Brasil (2018), que formulou o Programa Nacional de Educação Ambiental para a compostagem dos resíduos sólidos orgânicos, exercício esse que vem ganhando espaço nas instituições públicas, para melhoria constante do espaço de trabalho, pensando fortemente no fator ambiental.

Para realização da compostagem, foi pensado e arquitetado através da figura 1 registrada no diário de bordo. Posteriormente construída como maquete eletrônica, o protótipo da composteira foi organizado com furos na parte superior para a entrada de gás nitrogênio e sua absorção pelos fungos e bactérias, a mesma foi enterrada no solo e em seu entorno interior, foram colocados pedaços de espelhos que permitem o aquecimento suplementar, e posteriormente no telhado da casa-estufa, os painéis solares para carregar com eficiência as baterias a partir da conversão fotovoltaica. A sua aplicação foi realizada em uma área aberta em um terreno residencial.
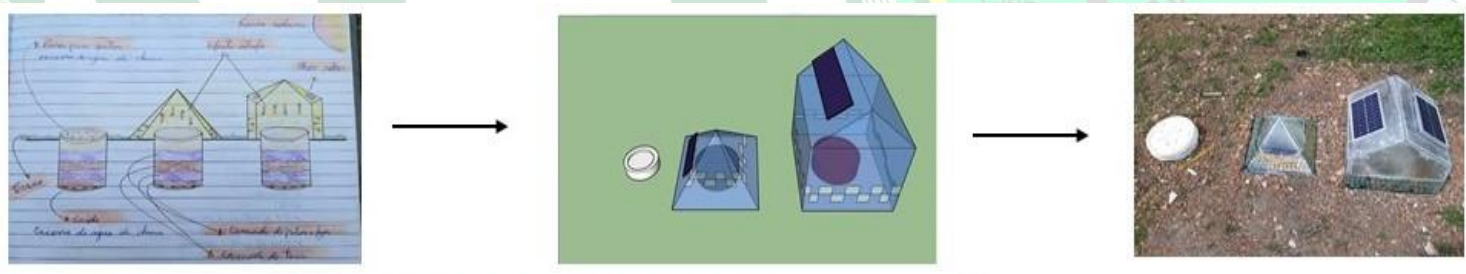

Figura 1 - Recorte do desenho e a construção da composteira. Fonte: Os autores, 2019.

Os processos de compostagem foram realizados em três diferentes composteiras, com três tipos de amostras. Na primeira "terra virgem"; na segunda foi acrescentado a "terra virgem" pelos de gatos e cães mais estercos de cães e na terceira também foi usada a mesma "terra virgem" com acréscimo a amostra dos pelos de gatos e cães mais estercos de gatos. Os 3 baldes de plástico de peso líquido $15 \mathrm{Kg}$ utilizados para o processo de compostagem foram perfurados nas tampas e no fundo, com furos de $7 \mathrm{~mm}$, recebendo $75 \%$ de terra virgem, $23 \%$ de esterco e $2 \%$ de pelos - gatos e cães. Esse processo ocorreu durante 60 dias no período de 01 de julho a 01 de setembro de 2019. Realizou-se reviramento do composto a cada 15 dias. 
Os pelos de gatos e cães foram acrescentados ao composto com intuito de substituir a tradicional fibra de coco, pois Silva e França (2013) realizaram testes com a incorporação da fibra de coco juntamente com estercos para produção de alface em comunidades rurais. Os pesquisadores perceberam uma maior capacidade de retenção de água observada nos solos incorporados com a fibra. Esse procedimento é de extrema importância, principalmente no ambiente rural. Os autores reforçam que, a utilização da fibra na horticultura dependerá dos tratamentos dispensados ao material; inclusive o cuidado com adição de outros componentes para aumentar ou diminuir a aeração e retenção de água.

Esta investigação é respaldada também nos estudos de Jacobi e Grandisoli (2017), os quais asseguram que, o caminho para a prática sustentável se faz com o fortalecimento de exercícios educativos na medida em que se desenvolva a sociedade, e que os paradigmas da complexidade sejam fragmentados, assim, os autores remetem-se para a importância da escola como aporte de intervenções e os ambientes pedagógicos uma atitude reflexiva em torno da problemática ambiental.

As atividades experimentais foram realizadas durante $10 \mathrm{~h}$ de registros da variação da temperatura em graus célsius através de um termômetro de mercúrio em três ambientes: fora da estufa, dentro da estufa-pirâmide e dentro da estufa-casa. Os testes foram documentados em três diferentes momentos: Primeiro momento foi um dia chuvoso; o segundo momento foi um dia ensolarado e o terceiro momento foi um dia ensolarado com aquecimento suplementar. As analises foram realizadas entre os dias 27 de junho e 01 de julho de 2019. Com clima chuvoso, a maior temperatura foi $48{ }^{\circ} \mathrm{C}$ às 14h dentro da estufa-pirâmide; no dia ensolarado, a temperatura máxima foi de $55{ }^{\circ} \mathrm{C}$ às 15h dentro da estufa-pirâmide. Como não atingiu a temperatura esperada, foi acrescentado um aquecimento suplementar nas estufas e feito nova análise, assim, registrou-se $62^{\circ} \mathrm{C}$ às $16 \mathrm{~h}$ dentro da estufa-casa com aquecimento suplementar.

Durante a realização da análise da temperatura em graus Celsius, foi documentado o tempo de carregamento total das duas baterias através do kit de energia solar com duas placas solares, onde cada bateria carregou em 18h.30min em dias diurnos, gerando fonte de energia limpa para carregar oito lâmpadas de led durante 8h. 
Tais testes foram realizados por respaldarem-se em Kiehl (1985), que afirma que, a temperatura, umidade e realizando-se o reviramento da matéria orgânica é um dos fatores mais importantes para definir quando a compostagem é feita de forma correta. $\mathrm{O}$ reviramento ocorreu a cada 15 dias e, durante cada reviramento, irrigou-se a matéria orgânica para distribuir bem a umidade. Assim, fornecendo metabolismos ao macro e micronutrientes em quantidades equilibradas que são responsáveis pelo excelente processo de compostagem.

A pesquisa também teve a preocupação no aquecimento suplementar, pois, respaldou-se nos estudos de Pereira (1989), que afirma que, a faixa de temperatura ideal para a decomposição da matéria orgânica oscila entre $50^{\circ} \mathrm{C}$ a $60^{\circ} \mathrm{C}$. A essas temperaturas, a matéria entra na chamada fase termófilifa, onde ocorre de maneira mais rápida a compostagem (KIEHL, 2014). Essas temperaturas mais elevadas contribuem também a extinguirem sementes infestantes, ovos de helmintos e quase todos os microrganismos patogênicos, os quais são poucos resistentes a baixas temperaturas (PEREIRA NETO, 1989). Reforça-se que, ultrapassando temperaturas de $70^{\circ} \mathrm{C}$, pode ocorrer a queima de microrganismos benéficos ao processo de compostagem, o que não é desejável nesta investigação.

Brito (2008) esclarece que, o processo de compostagem em pequena escala é uma opção viável para o reaproveitamento de resíduos em pequena escala, podendo ser construída nos quintais das residências - com a técnica correta. Destaca-se que, essa compostagem está menos susceptível a contaminações por outros materiais.

Nos resultados, ocorreram análises da temperatura no ambiente que confirmaram a aplicabilidade de sistemas fotovoltaicos em regiões do Brasil privilegiados com altas taxa de irradiação solar. Despontando qualidade na produção de energia e eficiência na distribuição. Assim, o projeto também propõe o empregado em regiões que não têm acesso à energia elétrica. De acordo com Villalva (2015), a energia fotovoltaica apresenta mais proporção em comparação à energia eólica, e que pode ser utilizada em todo território brasileiro.

O processo de compostagem não se limitou à adição e mistura de materiais orgânicos, mas envolveu outras características do material, como: $\mathrm{pH}$, temperatura, granulometria, concentração de umidade, seleção do sistema de compostagem, o local 
onde foi realizado. Desta forma, a compostagem se diferencia segundo aspectos físicoquímico e biológico dos seus diversos componentes. (KIEHL, 2014).

Realizaram-se análises químicas da "terra virgem" retirada a $15 \mathrm{~cm}$ de profundidade do solo. As amostras para análise foram coletadas e transportadas com inteira responsabilidade pelo pesquisador da intervenção. A análise química das amostras de terra para avaliação de fertilidade do solo consta na tabela 2.

Tabela 2 - Análise química das amostras

\begin{tabular}{|c|c|c|c|c|c|c|}
\hline \multirow{2}{*}{ Identificação } & pH & MO & $\mathbf{P}$ & $\mathbf{K}^{+}$ & $\mathrm{Ca}^{2+}+\mathrm{Mg}^{2+}$ & $\mathrm{Al}^{3+}$ \\
\hline & $\mathrm{H}_{2} \mathrm{O}$ & $\mathrm{g} / \mathrm{kg}$ & $\mathrm{Mg} / \mathrm{dm}^{3}$ & & $\mathrm{Cmol}_{\mathrm{d}} / \mathrm{dm}_{3}$ & \\
\hline Terra virgem & 5,5 & 146,54 & 8 & 0,26 & 15,2 & 0,0 \\
\hline Interpretação de análise & Médio & $\begin{array}{l}\text { Muito } \\
\text { Baixo }\end{array}$ & Baixo & Bom & $\begin{array}{l}\text { Muito } \\
\text { Bom }\end{array}$ & $\begin{array}{l}\text { Muito } \\
\text { Baixo }\end{array}$ \\
\hline Pelos+Estercos Cães & 5,7 & 117.23 & 208 & 0,33 & 19,2 & 0,0 \\
\hline Interpretação de análise & Médio & $\begin{array}{c}\text { Muito } \\
\text { Bom }\end{array}$ & $\begin{array}{c}\text { Muito } \\
\text { Bom }\end{array}$ & $\begin{array}{l}\text { Muito } \\
\text { Bom }\end{array}$ & $\begin{array}{l}\text { Muito } \\
\text { Bom }\end{array}$ & $\begin{array}{l}\text { Muito } \\
\text { Baixo }\end{array}$ \\
\hline Pelos+Estercos Gatos & 5,8 & 125,85 & 227 & 0,42 & 19,7 & 0,0 \\
\hline Interpretação de análise & Médio & $\begin{array}{c}\text { Muito } \\
\text { Bom }\end{array}$ & $\begin{array}{c}\text { Muito } \\
\text { bom }\end{array}$ & $\begin{array}{c}\text { Muito } \\
\text { Bom }\end{array}$ & $\begin{array}{c}\text { Muito } \\
\text { Bom }\end{array}$ & $\begin{array}{l}\text { Muito } \\
\text { Baixo }\end{array}$ \\
\hline
\end{tabular}

Fonte: Embrapa, 2019.

A partir das análises químicas, observou-se que o estercos canino apresentou relevância nos aspectos: potencial hidrogênionico com 5,7 (levemente ácido). Assim, valores baixos de $\mathrm{pH}$ são referentes à ausência de maturação devido à curta duração do processo ou à ocorrência de processos anaeróbios no interior da composteira. Posteriormente, estes ácidos são decompostos até serem totalmente oxidados. Ressaltase, se existir escassez de oxigênio, o $\mathrm{pH}$ poderá diminuir a valores inferiores a 4,5 e limitar a atividade microbiana, retardando, assim, o processo de compostagem. A amostra também teve relevantes qualidades em fósforo, potássio, cálcio e magnésio.

Mas, ressalta-se que o melhor resultado químico foi na amostra que continha “terra virgem", pelos de gatos e cães mais estercos de gatos, pois através da análise química se observou o melhor resultado no aspecto: potencial hidrogeniônico com 5,8 (médio). No Brasil, a maioria dos solos é considerada fortemente ácida (pH entre 5,0 e 5,5). Porém, solos muito ácidos não são férteis porque a disponibilidade de nutrientes é muito pequena para as plantas, assim, não conseguem crescer, tendo que haver um 
equilíbrio entre estes valores. A utilização de adubação orgânica favorece a química do solo, deixando-o com pH próximo do neutro (NÓBREGA, 2015).

Ainda na amostra de "terra virgem", pelos de gatos e cães mais estercos de gatos destacou excelentes resultados nos aspectos: fósforo $(\mathrm{P})$ com $227 \mathrm{Mg} / \mathrm{dm} 3$, potássio $(\mathrm{K})$ com 0,42 Cmolc/dm3, cálcio (Ca) e magnésio (Mg) com 19,7 Cmolc/dm3.

De acordo com a Empresa Brasileira de Pesquisa Agropecuária (Embrapa), o potássio (K) é responsável pelo desenvolvimento das plantas e pela absorção de água, se o potássio está baixo as plantas não ficam saudáveis e tornam-se vulneráveis à doenças e parasitas. Além disso, sem potássio as plantas não conseguem fazer com que os nutrientes circulem corretamente.

Assim, Fontes (2006) afirma que, os nutrientes apresentam distintas funções nos vegetais e a sua deficiência pode causar uma infinidade de sintomas característicos para cada elemento, os quais são exteriorizados por sintomas típicos. O diagnóstico de problemas nutricionais, mediante à observação de sintomas, tem grande importância, pois permite tomar decisões instantâneas no campo para a correção das deficiências.

Nas análises granulométricas, o laboratório da Embrapa Brasileira de Pesquisa Agropecuária (Embrapa), apresenta classes de tamanho: $(<0,002 \mathrm{~mm})$, silte $(0,002 \mathrm{a}$ $0,05 \mathrm{~mm})$, areia fina $(0,05$ a $0,2 \mathrm{~mm})$ e areia grossa $(0,2$ a $2 \mathrm{~mm})$. Assim, é possível avaliar as amostras do composto com pelos de gatos e cães mais estercos de gatos e cães.

As atividades experimentais foram realizadas com três grupos. O primeiro grupo: "terra virgem"; o segundo: "terra virgem", pelos de gatos e cães mais estercos de cães; e o terceiro grupo com "terra virgem", pelos de gatos e cães mais estercos de gatos. Para os testes foram utilizados vegetais da Família: Lactuca sativa do Gênero: Lactuca com nome popularmente conhecido como alface.

Foram depositados em cada vaso de plásticos $4 \mathrm{~kg}$ de cada amostra, as amostras 2 e 3 continham $-75 \%$ de " terra virgem", $23 \%$ de esterco e $2 \%$ de pelos e cultivou-se 2 mudas em cada vaso, assim, cultivando 8 mudas em cada um dos três grupos, mantevese em ambiente natural. Os cultivos foram assim denominados: 
Grupo 1: Grupo Branco - Cultivo realizado sobre o solo (terra virgem coleta a $15 \mathrm{~cm}$ de profundidade). Recebeu pela parte da manhã e tarde $250 \mathrm{~mL}$ de água em cada recipiente, diariamente.

Grupo 2: Grupo Controle - Cultivo realizado sobre o solo (terra virgem coleta a $15 \mathrm{~cm}$ de profundidade, composto após 90 dias com pelos de gato e cães mais estercos de cães). Recebeu pela parte da manhã e tarde $250 \mathrm{~mL}$ de água em cada recipiente, diariamente.

Grupo 3: Grupo Controle - Cultivo realizado sobre o solo (terra virgem coleta a $15 \mathrm{~cm}$ de profundidade, composto após 90 dias com pelos de gato e cães mais estercos de gato). Recebeu pela parte da manhã e tarde $250 \mathrm{~mL}$ de água em cada recipiente, diariamente. Desta forma, após os 30 dias de cultivo em ambiente natural e recebendo o mesmo quantitativo de água diariamente, foi realizada a pesagem da biomassa dos três diferentes grupos.

Após o termino das análises avaliativas de todos os grupos, que se estendeu durante 30 dias, foi realizada uma análise comparativa do crescimento e peso da biomassa das folhas e raízes de alface nos diferentes tipos de adubo. Após a colheita, foi feita a limpeza e secagem das raízes, caules e folhas, e posteriormente pesados. Os dados dessa atividade ficaram registrados na Tabela 3.

Tabela 3 - Pesagem quanto ao kg e o crescimento das biomassas

\begin{tabular}{ccccc}
\hline ITEM & CRITÉRIO & $\begin{array}{c}\text { GRUPO } \\
\text { BRANCO } \\
\text { Terra } \\
\text { virgem }\end{array}$ & $\begin{array}{c}\text { GRUPO } \\
\text { CONTROLE I } \\
\text { Terra Virgem + } \\
\text { Pelos + estercos de } \\
\text { cães }\end{array}$ & $\begin{array}{c}\text { GRUPO } \\
\text { CONTROLE II } \\
\text { Terra Virgem + } \\
\text { Pelos + estercos de } \\
\text { gato }\end{array}$ \\
\hline $\mathbf{0 1}$ & Total & 8 & 8 & 8 \\
\hline $\mathbf{0 2}$ & Morreram & - & - & - \\
\hline $\mathbf{0 3}$ & Descartados & - & - & - \\
\hline $\mathbf{0 4}$ & Peso Folha & $41 \mathrm{~g}$ & $478 \mathrm{~g}$ & $136 \mathrm{~g}$ \\
\hline $\mathbf{0 6}$ & Peso do Caule & $6 \mathrm{~g}$ & $116 \mathrm{~g}$ & $26 \mathrm{~g}$ \\
\hline $\mathbf{0 7}$ & Peso da raiz & $9 \mathrm{~g}$ & $25 \mathrm{~g}$ & $18 \mathrm{~cm}$ \\
\hline $\mathbf{0 8}$ & Maior Folha & $11 \mathrm{~cm}$ & $16,5 \mathrm{~cm}$ & $3,5 \mathrm{~cm}$ \\
\hline
\end{tabular}

Fonte: Oliveira, 2019.

Conforme registrado na Tabela 3, a utilização de pelos e estercos de gatos e cães, apresentou relevância significativa no desenvolvimento das plantas. Apresentando 
resultados satisfatórios para aplicar em hortas totalmente sustentáveis, o que corresponde ao quarto objetivo desta pesquisa que, é oferecer melhor qualidade na produção agrícola, bem como cumprir com o objetivo número 2 da Agenda 2030, estipulada pela ONU. Dessa forma, foi possível registrar:

Grupo 1: Grupo Branco - Cultivo realizado sobre o solo (terra virgem coleta a $15 \mathrm{~cm}$ de profundidade). Registrou-se um desenvolvimento lento no crescimento das folhas, caule e raízes. Nas observações, foi possível identificar o crescimento máximo da folha de $11 \mathrm{~cm}$, a menor folha com $2,5 \mathrm{~cm}$. Ainda, somou-se o peso das folhas em $41 \mathrm{~g}$ e das raízes com $9 \mathrm{~g}$.

Grupo 2: Grupo Controle - Cultivo realizado sobre o solo (terra virgem coleta a $15 \mathrm{~cm}$ de profundidade, composto após 90 dias com pelos de gatos e cães mais estercos de cães). Registrou-se um desenvolvimento muito bom no crescimento das folhas, caule e raízes. Nas observações, foi possível identificar o crescimento máximo da folha de $16,5 \mathrm{~cm}$, a menor folha com $3,0 \mathrm{~cm}$. Ainda, somou-se o peso das folhas em $478 \mathrm{~g}$ e das raízes com $25 \mathrm{~g}$.

Grupo 3: Grupo Controle - Cultivo realizado sobre o solo (terra virgem coleta a $15 \mathrm{~cm}$ de profundidade, composto após 90 dias com pelos de gato e cães mais estercos de gatos). Registrou-se um desenvolvimento excelente no crescimento das folhas, caule e raízes. Nas observações, foi possível identificar o crescimento máximo da folha de $18,0 \mathrm{~cm}$, a menor folha com $3,5 \mathrm{~cm}$. Ainda, somou-se o peso das folhas em $507 \mathrm{~g}$ e das raízes com $26 \mathrm{~g}$.

Desta forma, os resultados obtidos reafirmam que, a eficácia da adubação não depende exclusivamente das doses ou quantidades a serem aplicadas. Outros fatores devem ser do conhecimento do técnico e/ou agricultor, para que conduzam a um melhor uso dos adubos (BARRETO; FERNANDES, 2002; LACERDA et al., 2006).

A técnica aplicada é uma alternativa a ser considerada na gestão de resíduos sólidos. Além de reduzir os volumes que estariam dispostos pela limpeza urbana, é uma operação de baixo custo, sem necessidade de transporte ou muito espaço (OLIVEIRA et al., 2017).

Desta maneira, registra-se a importância de pesquisas voltadas para o Ensino de Ciências, pois para Hendge (2019) a provocação a partir de alternativas de ensino vem 
permitindo melhorar os processos de ensino e de aprendizagem, sem limitações do espaço educacional.

Ademais, a pesquisa convergiu com o aporte teórico de Caco de Paula (2007), que assegura que, a sustentabilidade é abrangida como elemento que consente as precisões do presente sem afetar as possibilidades de as futuras gerações consentirem às suas próprias necessidades, isto é, o indivíduo não deve excepcionalmente olhar o impacto imediato de um projeto, mas como esse projeto impactará futuras gerações nos seus diferentes benefícios e respostas a tais problemáticas.

\section{CONSIDERAÇÕES}

A inquietação com a problemática socioambiental e a sustentabilidade nesta pesquisa apresentou papel fundamental, pois foi possível encontrar técnicas capazes de desenvolver a construção de uma composteira que atendeu os objetivos propostos nesta investigação, com possível capacidade de contribuição para que as próximas gerações supram suas necessidades específicas. Ou seja, a humanidade requer preservar seu padrão de vida e sustentar o progresso tecnológico sem afadigar os recursos naturais do planeta.

A investigação permitiu resultados durante as atividades experimentais que levam a conclusão de que é possível aproveitar pelos e estercos de gatos e cães, por meio de inovações alternativas que possam garantir que o composto final irá enriquecer o solo e os vegetais, acendendo riquezas nutricionais, químicas e biológicas para essas plantas; permitindo qualidade no processo da agricultura. Ratifica-se ainda que, esta pesquisa tem anexo placas solares que permitiram a produção de energia elétrica limpa a partir da conversão fotovoltaica.

Ademais, apresentamos formas de aproveitamentos de pelos e estercos de gatos e cães e energia fotovoltaica como fruto de técnicas sustentáveis para implementação na agricultura e comunidades carentes, resolvendo uma questão socioambiental, instigando e apreciando as construções do conhecimento do empírico ao científico, junto à construção de diferentes olhares para tais resíduos, permitindo ambientes mais agradáveis - plantas, mais produção de $\mathrm{O}_{2}$ e sensibilidade ambiental à sociedade individual e em geral. 


\section{REFERÊNCIAS}

BARRETO, A. C.; FERNANDES, M. F. Produtividade e absorção de fósforo por plantas de milho em função de doses e modos de aplicação de adubo fosfatado em solo de tabuleiro costeiro. Revista Brasileira de Ciência do Solo, v. 26, n. 02, p. 151$156,2006$.

BRASIL. Ministério do Meio Ambiente. Educação ambiental: por um Brasil sustentável - ProNEA, Marcos Legais \& Normativos. 5. ed. Ed. Ministério do Meio Ambiente -MMA, Ministério da Educação - MEC,- Brasília, DF: MMA, 2018. 104 p. Disponível em: <http://www.mma.gov.br/publicacoes/educacao-ambiental/category/98pronea.html>. Acesso em: 08 set. 2019.

BRITO, M. J. C. Processo de compostagem de resíduos urbanos em pequena escala e potencial de utilização do composto subtrato. 2008. $124 \mathrm{f}$. Dissertação (Mestrado). Pós-graduação em Engenharia de Processos, Universidade Tiradentes. Aracaju, 2008.

FONTES, P. C. R. Diagnóstico do estado nutricional das plantas. Viçosa: Universidade Federal de Viçosa, 3a ed., 122p, 2006.

FRANÇA, J.; SAAD, B. O. M. F.; SAAD, P. E. C.; SILVA, C. R. \& REIS, S. J. (2011). Avaliação de ingredientes convencionais e alternativos em ração de cães e gatos. Revista Brasileira de Zootecnia, 40:222-231.

GIL, A. C. Métodos e técnicas de pesquisa social. $6^{\text {a }}$ ed. 5. Reimpr. São Paulo: Atlas, 2012.

GRÁCIO, M. M. C.; GARRUTTI, É. A. Estatística aplicada à educação: uma análise de conteúdos programáticos de planos de ensino de livros didáticos. Revista de Matemática e Estatística, São Paulo, v. 23, n. 3, p.107-126, abr. 2005.

HENDGES, A. P. Estágio não formal: vivenciando experiências com a Educação Especial. Revista Insignare Scientia - RIS, v. 2, n. 3, p. 21-30, 21 nov. 2019.

IBGE. INSTITUTO BRASILEIRO DE GEOGRAFIA E ESTATÍSTICA. Censo 2013. Disponível em: http://www.ibge.gov.br. Acesso em 02/06/2019.

JACOBI, P. R.; GRANDISOLI, E. Água e sustentabilidade: desafios, perspectivas e soluções. São Paulo: IEE-USP e Reconectta, p. 110, 2017.

KIEHL, E. J. Manual de compostagem: maturação e qualidade do composto. 4.ed. Piracicaba, 2014.

KNECHTEL, M. R. Metodologia da pesquisa em educação: uma abordagem teóricoprática dialogada. Curitiba: Intersaberes, 2014. TOZONI-REIS, Marília Freitas de Campos. 
LAKATOS, E.; MARCONI, M. Metodologia científica. 6. Ed. São Paulo: Editora Atlas, 2011.

NÓBREGA, J. Q. A importância do uso do esterco bovino para recuperar solos degradados. 2015. Disponível em: http://nordesterural.com.br/a-importancia-do-usodo-esterco-bovino-para-recuperar-solos-degradados/. Acesso em: 22 de agosto de 2019.

OLIVEIRA, L.S.B.L.; OLIVEIRA, D.S.B.L.; BEZERRA, B.S.; PEREIRA, B.S.; BATISTTELLE, R.A.G. Environmental of analysis of organic waste treatment focusing on composting scenarios. Journal of Cleaner Production, v.155, p.229-237, 2017.

PAULA, Caco de. O futuro a gente faz agora. Planeta Sustentável. ed. Abril, 2007.

PENTEADO, S.R. Manual prático de agricultura orgânica: fundamentos e técnicas. 2. ed. Campinas: Via orgânica, 2013.

PEREIRA NETO, J. T. Conceitos Modernos de Compostagem. Engenharia Sanitária, v.28, n.3, 1989.

THIOLLENT, M. Metodologia da pesquisa-ação. São Paulo: Cortez, 2011.

VILLALVA, M. G. Energia Solar Fotovoltaica. 2 Ed. São Paulo. Érica. 2015. 